\title{
"QUANTA MUTAÇÃO E TUMULTO, QUANTO REBULIÇO E CONFUSÃO NESSA HISTÓRIA!" SEGUINDO OS FIOS NARRATIVOS DE BRUNO SCHULZ
}

Michael Korfmann*

Resumo: A obra de Schulz é frequentemente situada entre os polos da memória individual e do mito universal. Bem menos atenção é dada ao elemento irônico e paródico que exerce um papel central nos textos do autor. Este artigo visa compreender sua obra dentro de uma perspectiva que julga o elemento irônico e paródico como parte de uma encenação literária em que personagens e momentos emergem irônica, cômica e tragicamente na constituição do "grande sentido universal" apenas para, logo depois, se revelarem atores fugazes e falsas esperanças da rede dos eternos fios narrativos.

Palavras-chave: Bruno Schulz. Mito. Ironia.

B runo Schulz (1892-1942) nasceu no vilarejo de Drohobycz, o qual, parte do Império Austro-Húngaro de então, passou ao domínio da Polônia ao fim da Primeira Guerra Mundial e ainda pertenceu brevemente à União Soviética no início da Segunda Guerra Mundial, até ser tomado pelos alemães, em 1941. Em virtude da invasão alemã, Schulz - um pacato professor de desenho com dois livros de contos publicados - é forçado, por ser judeu, a viver no gueto de Drohobycz. Em 1942, morreu fuzilado por um oficial alemão.

No Brasil, sua Ficção completa foi publicada em 2012. A obra reúne as duas coletâneas de contos lançadas por Schulz, Lojas de canela, de 1934, e Sanatório sob o signo da clepsidra, de 1937 (que já haviam saído no país pela Imago nos anos 1990), acrescidas de quatro contos inéditos em português e de ilustrações do próprio Schulz.

O interesse internacional pela obra literária e em menor medida pela obra gráfica de Bruno Schulz se deve em parte ao escritor americano Jonathan Safran 
Foer (2003, 2010). Há uma série de referências schulzianas na obra de Foer. Já o título de seu primeiro romance, Everything is illuminated de 2002, aponta para o exposé de Schulz à sua Lojas de canela onde a atmosfera sombria, cheia de pressentimentos, uma aura "que engrossa em torno da família, iluminando-a, miticamente, como um relâmpago [...] abre ao poeta o acesso àquela outra face [...] àquela versão mais profunda da história" (SIERWIERSKY, 1996, p. 155). Em 2009, Foer escreveu o prefácio para uma nova edição de The streets of crocodile, título inglês de Lojas de canela, publicada pela Penguin Books e, em 2010, lançou Tree of codes, que usa The streets of crocodile como pano de fundo. Aplicando uma técnica conhecida como die-cut, cortando e pinçando o texto original de Schulz, transforma-o num livro novo de 134 páginas, de destacada plasticidade, com menos de três mil palavras de teor gráfico. Em relação ao título, por exemplo, eliminou sete letras da versão original em inglês, obtendo assim Tree of codes. Dessa forma, todas as palavras e, às vezes, até frases completas do livro de Foer estão contidas no texto de partida de Schulz.

Obviamente, Foer aplica, em Tree of codes, a ideia consagrada de um subtexto a partir do qual podem surgir novos textos, significados ou versões mais densas em uma obra híbrida entre o textual e o visual. O próprio Schulz (1994, p. 137) se refere a "sábios palimpsestos de diversas camadas" e comenta, numa carta a Romana Halpern, sobre sua leitura do livro de um autor polonês: "Atrás deste livro vejo os contornos de um outro livro que eu gostaria de escrever. Não sei bem se estou lendo este livro ou o potencial não realizado" (SCHULZ apud DULAIMI, 1975, p. 21).

Nesse sentido, Foer pode invocar o próprio Schulz quando insiste, numa entrevista concedida à Heather Wagner (2010, tradução nossa), que "este livro é meu. Seu livro é uma obra-prima, o meu foi uma experiência pessoal. Minha história não tem nada a ver com a sua história" e defende a ideia de que tal procedimento criativo faz parte de toda produção literária: "Há a sensação de que todos os livros são escritos assim, caso se use o dicionário como ponto de partida. Referente ao meu livro, há uma gama de palavras mais limitada, mas é a mesma ideia" (WAGNER, 2010, tradução nossa).

Se Foer parte de um texto de Schulz como uma fonte delimitada, um pano de fundo disponivel para gerar seu Tree of codes, o próprio Schulz usa o cotidiano de sua infância como base para suas narrativas entremeadas de lembranças com olhar infantil ou adolescente e de certa mitificação do tempo na qual transparece, a partir da memória individual e episódica, sua inserção no universal atemporal. Referindo-se à fonte de sua literatura, Schulz (1981, p. 160) escreve: "De onde os escritores iriam colher sua matéria, de onde eles receberiam a coragem de fabular, se eles não sentissem essas reservas, esses capitais, essas centenas de diversificações atrás de si, vibrando no submundo?”. Objetivamos a seguir entender como tais "capitais" são tratados na obra de Bruno Schulz.

Numa carta de 1935 ao seu colega escritor Witkiewicz, Schulz (1936, p. 164-165) aborda, de forma mais explícita a relação entre o fundo mítico, confiado sobretudo ao artista, e o seu próprio trabalho.

Essas imagens prematuras determinam aos artistas os limites da sua criação, que é uma dedução dos princípios feitos. Depois já não descobrem nenhuma

As traduções do alemão são do autor. 
coisa nova, aprendem apenas a entender cada vez melhor o segredo que thes foi confiado no início. [...]. Aliás, a arte não desvenda este segredo até o fim. Ele permanece indestrinçável. O nó em que a alma foi amarrada não é um nó falso que se desfaz com o puxão de uma ponta. Ao contrário, ele fica cada vez mais apertado. Nós o manipulamos, seguimos o curso dos fios, procuramos o fim, $e$ dessas manipulações nasce a arte.

Nessa mesma carta, ao usar expressões como "entender o segredo", "uma exegese incessante" ou "um comentário àquele versículo que lhes foi passado" em uma reflexão sobre a tarefa do escritor, Schulz já aponta para duas linhas básicas de sua obra: em primeiro lugar, a questão de memória e, em segundo, o mito ou a mitologia. Ele mesmo não parece fazer distinção entre ambos e os usa indiscriminadamente. Podemos aqui evocar uma definição tradicional que atribui ao mitológico o tratamento irônico - isto é, autoconsciente - do mito, de tal maneira que "a maioria da literatura moderna, que apresenta elementos míticos, deve ser, por causa de sua configuração irônica dos mesmos, definida como mitológica" (GRIMM; HERMAND, 1970, p. 177). Encontramos o mitológico em duas formas nos textos de Schulz. Primeiro em elementos, motivos ou figuras, frequentemente análogos aos motivos bíblicos, bem como em máscaras e paródias. Assim, surge num dos seus contos um andarilho com ares de deus Pã; num outro, o pai do narrador assume, em certos momentos, aparências de um profeta do Velho Testamento; e há ainda o caso da empregada Adela, que é apresentada como a deusa Pomona. A segunda forma do mito está ligada ao sentido primordial da linguagem.

Cada elemento da realidade vive ao participar de um sentido universal. As velhas cosmogonias resumiram isso na frase: "No início era a Palavra". O que é sem nome não existe para nós. Denominar algo significa integrá-lo num sentido universal. A palavra isolada, a palavra como abáculo é um produto posterior; ela já é um resultado da técnica. A palavra primordial era uma forma fantástica que circunscrevia o sentido do mundo; ela era um grande todo universal (SCHULZ, 2008, p. 193).

Se, no decorrer da civilização, as necessidades da comunicação cotidiana tornaram a linguagem mais funcional e reduzida, a mitologização da realidade é, conforme Schulz, a recondução da palavra para sua função original e autêntica, a de produzir um sentido amplo e atemporal que permita ter uma noção da ordem primordial do mundo, sem que essa seja totalmente alcançável e o segredo desvendável. A ligação entre memória e mitologia realiza-se, na obra de Schulz, por meio da elaboração literária da infância, chamada por ele de "época genial", a "grande temporada" ou a "república de sonhos". A respeito disso, Schulz (2000, p. 90 e 107) escreve: "Não sei como, na infância, certas imagens ganham significado decisivo para nós. [...] Elas realizam o papel de fios condutores e a seus redores se cristaliza para nós o sentido do mundo".

Se Lojas de canela (SCHULZ, 1996) e sua continuação, o volume Sanatório (SCHULZ, 1994), tratam da recuperação da infância por meio da mitificação do tempo, esse processo não deve ser compreendido como uma reprodução, mas sim como uma busca constitutiva onde a realidade é "a sombra da palavra" (SCHULZ, 1936, p. 172). Trata-se, então, de despertar, por meio da palavra, o estado primordial, o caos amorfo e acompanhar o curso dos fios numa realidade 
que se encontra num estado de fermentação permanente, revestindo-se de certas aparências apenas para fingir e brincar, numa constante migração de formas em que a grandeza primordial, una e indivisivel, apenas se vislumbra no horizonte como fonte potencial das variações e diversificações experimentáveis.

Tanto nos episódios de Lojas de canela como nos de Sanatório, tal busca do primordial, da maturidade da infância, realiza-se por meio de um narrador em primeira pessoa. Os pontos centrais, que de certa forma interligam os diversos episódios, são o pai, sua loja e um livro sagrado e misterioso. Os acontecimentos se passam em dois niveis temporais: na fase histórica de sua infância por volta de 1900 e, paralelamente, num tempo complementar, não linear mas cíclico, de maneira que os diversos episódios nos dois volumes frequentemente retomam e evocam narrativamente motivos ou momentos do tempo sucessivo. Schulz desconstrói e questiona o tempo real por meio dessas voltas periódicas a um tempo alternativo, revezando memórias narradas da perspectiva de um jovem com a transposição dessas a contextos mais atemporais ou mitológicos. Schulz realiza tal mistificação do tempo ao usar recursos linguísticos como a repetição de formas verbais iterativas e incompletas e, no aspecto narrativo, ao atribuir uma suposta sacralidade a objetos ou atividades cotidianos e banais, elevando-os à dignidade de cerimônias. Assim, um almoço comum assume feições de um ritual secreto, e um folheto de propaganda pode tornar-se um livro sagrado. Mas a manifestação do mito universal no cotidiano, a suspensão da divisão do tempo em passado, presente e futuro, e a dissolução da infância particular de Schulz na infância da humanidade não se realizam de forma clara, mas sempre de maneira ambígua, pois tais suspensões de conflito entre o prosaico ou banal e o eterno mitológico podem ser apenas ilusões autorreflexivas do narrador num permanente labirinto de fios e níveis narrativos.

Em face de tal complexidade e nós textuais indissolúveis, muitas interpretações - a fim de apresentar um quadro analítico linear e inequívoco - tendem a enfatizar as referências externas dos textos de Schulz. Assim, em Ficowski (2008, p. 28), o contexto biográfico serve como explicação para sua produção literária: "As primeiras tentativas de escrever, realizadas secretamente por Bruno, foram a ressurreição mítica de seu pai" - isto é, Bruno teria tentado anular, no mito, o que aconteceu de fato na realidade, a saber, o falecimento de seu pai em 1915, quando Bruno tinha 23 anos. Privilegia-se nos textos a mera transposição literária de temas como a relação de poder entre pai e filho (cf. GOŚLICKIBAUR, 1975) ou a tradição judaica (cf. SCHULTE, 2004). Schmid (2004, p. 119) entende a obra de Schulz como "transposição fiel de três narrativas básicas da modernidade européia, as de Kant, Freud e Kafka”. O elo entre infância e psicanálise frequentemente representa o ponto de partida de tais estudos. Olchanowski (2001), por exemplo, interpreta a figura do pai nos textos de Schulz como arquétipo no sentido de C. G. Jung, enquanto Katarzyna Lukas (2010) amplia essa visão ao investigar sua prosa no contexto das ideias de Thomas Mann e Jung, traçando uma ligação entre Freud, Mann e Schulz. Ela parte de uma declaração de Mann (1953, p. 212), que, numa homenagem a Freud, afirmara que "o interesse mítico faz parte da psicanálise como o interesse psicológico do trabalho poético. Sua penetração na infância da alma singular é paralelamente também a penetração na infância do homem, no primitivo e no mito". A autora recorre ainda ao próprio Schulz, que revela sua admiração a Thomas Mann pois em sua obra encontrar-se-ia a 
[...] existência de certos esquemas primordiais no fundo de todos os acontecimentos humanos quando descascados do invólucro do tempo e da variação; são histórias a partir das quais esses acontecimentos se formam como grandes repetições (SCHULZ apud DULAIMI, 1975, p. 8).

Mas o "descascar do invólucro" a fim de obter uma perspectiva do mítico absoluto na obra de Schulz não conduz a uma revelação estática, a uma conclusão estável e definitiva. Nos textos literários de Schulz, há sempre uma indiferenciabilidade, um nó narrativo e um perspectivismo que resistem a ser sistematizados em uma teorização lógica rigorosa. E, conforme a própria teoria do Schulz, é necessário que eles mantenham tal qualidade, pois, como escreve acerca da relação entre mitologia e linguagem:

O fundo do mito precisa continuar a manter contato com o incompreensível $e$ pré-literal se quer ser vivo e enraizado na obscura pátria mítica. A obscuridade do mito é a expressão nítida da história atual: o poeta precisa navegar seu barco entre tais recifes de Cila e Caribdis (SCHULZ, 1967, p. 63)

o que resulta em desdobramentos, sombras, paralelismos, espelhamentos e consequentemente narrativas com múltiplas perspectivas. No episódio Primavera, Schulz (1994, p. 67-71) guia-nos a tal "obscura pátria":

Será que chegamos ao fundo, será que este caminho não leva a mais lugar nenhum? Estamos no fim das nossas palavras, que aqui se tornam delirantes, disparatadas e irresponsáveis. [...] Só além das nossas palavras, onde a força da nossa magia já não alcança, sussurra este elemento obscuro e imenso. A palavra se decompõe em fatores e se dissolve, retorna à sua etimologia, entra de novo no fundo, na sua raiz obscura. [...] Que circulação, que movimento, que turba! Que formigueiro e polpa, quantos povos e gerações, bíblias e iliadas multiplicadas por mil! Quanta migração e tumulto, quanto rebuliço e confusão da história! [...] Estamos no próprio fundo... [...]. Aqui se encontram as grandes incubadoras das histórias, as fábricas fabuladoras, as nebulosas salas das fábulas e contos de fadas. [...] Há tantas histórias não nascidas. Oh, esses coros lastimáveis entre as raizes, essas conversas, esses monólogos inesgotáveis...

Não se trata, portanto, na literatura de Schulz, da mera regressão ao passado: a partir da presentificação do passado na memória, ocorre a produção de um sentido mais abrangente, apontando para além do efêmero, para a "obscura pátria mítica" como fundo eterno que possibilita a realização de formas concretas e experimentáveis. Essa "pátria" abstrata precisa de formas concretas, variações atuais da potencialidade desse fundo para se afirmar. Na obra de Schulz, essa dependência mútua entre forma concreta e o potencial envolve, em nossa leitura, uma arbitrariedade textual, uma oscilação entre o atual e o potencial, bem como a tendência a vertiginosos movimentos labirinticos. Tentaremos, a seguir, exemplificar tais procedimentos em certos episódios extraídos de Lojas de canela e Sanatório.

Iniciamos com $A$ visitação, o segundo episódio do primeiro volume. "Visitação" significa aqui, de um lado, a "visita" inicial da morte, sua penetração no ambiente e no corpo do pai, e, de outro, o acometimento com a doença que vai derrotá-lo.

Schulz (1996, p. 22) inicia esse episódio de transição da vida "normal" para uma fase marcada pela deterioração referindo-se a uma época em que "nossa 
cidade caía cada vez mais no cinzento crônico do crepúsculo, cobria-se nas suas margens do líquen da sombra, de mofo penugento e musgo cor de ferro". A sensação de declínio, de um clima sombrio e de incertezas já no início da narrativa é reforçada pelo fato de que a família mora na praça, "numa dessas casas escuras de fachadas vazias e cegas, tão dificeis de distinguir uma da outra” (p. 22), o que leva tanto os visitantes como os próprios moradores a frequentes enganos e à sensação de se encontrarem em um labirinto. A casa do narrador, cada vez mais "num estado abandono" (p. 23), não tinha "um número definido de quartos, porque ninguém se lembrava quantos deles eram alugados" para vendedores visitantes, que se deitavam em "lençóis sujos", tinham "pés feios" (p. 23) e de manhã bocejavam "até a contratação dolorida do céu da boca, como vômitos muito fortes" (p. 24). Nos cantos do quarto "ficavam sentadas, imóveis, enormes baratas". Foi nessa época que "meu pai começou a ter problemas de saúde" (p. 24), que resultaram em um "cheiro amargo" que "assentava no fundo do quarto" e também em oscilações de humor, em que o pai alterna momentos de irritação com outros mais calmos e nos quais consegue concentrar-se no trabalho. Faz parte da doença ou de seu tratamento "certo instrumento de confiança" (p. 25), um vidro cheio de fluido escuro. O pai se liga a esse instrumento "através de um intestino comprido de borracha, feito um tortuoso e dolorido cordão umbilical" e, deitado de maneira imóvel, aparecem-lhe no rosto "sinais de um sofrimento ou de um prazer pecaminoso" (p. 25). Nessa fase transitória, o tempo sucessivo e o real referencial externo começam a se expandir, mesclar ou confundir com um tempo ou existência paralela. Quando o pai senta

[...] à luz da lâmpada da mesa [...] ou se agitava no alto à sombra do abajur, sombra que o ligava ao grande elemento da noite urbana além da janela - sentia, sem olhar, que o espaço o cobria com uma brenha de papel de parede pulsante, cheia de sussurros, silvos e ceceios. Ouvia, sem olhar, esse complô cheio de piscadelas secretas, olhos de gatos, lábios escuros que sorriam, e conchas de orelha que escutavam desabrochando entre as flores (SCHULZ, 1996, p. 25).

Com seu estado de saúde piorando, levanta, certa noite,

[...] exigindo que the desse um testemunho com sua boca e suas entranhas. E ouvimos o espírito entrando nele, ouvimos como se levantava da cama, alto $e$ crescente com a ira de um profeta, engasgando com as palavras barulhentas que atirava feito uma metralhadora. Ouvimos o estalido da luta e o gemido do pai, um gemido de titã de quadril quebrado, que ainda não para de xingar.

Nunca vi os profetas do Velho Testamento, mas ao olhar este homem, derrubado pela ira de Deus, escarranchado largamente sobre o enorme urinol de porcelana, coberto pelo turbilhão de braços, pela nuvem de brandimentos desesperados, sobre os quais pairava ainda sua voz dura e estranha-percebi a ira divina dos santos varões.

Era um diálogo terrível como a fala dos trovões. O brandir das suas mãos rasgava o céu em pedaços, e nas frestas aparecia o rosto de Jeová, inchado de cólera e cuspindo pragas. Vi, sem olhar, o terrivel Demiurgo, que deitado nas trevas como no monte Sinai, apoiando suas poderosas mãos no cortinado, encostava o rosto nos vidros superiores da janela, achatando monstruosamente seu nariz carnudo (SCHULZ, 1996, p. 26-27). 
A narrativa de teor místico logo cede lugar a uma observação mais prosaica. "À luz do relâmpago vi meu pai, de pijama desabotoado, despejando de um único e poderoso golpe, com uma terrivel praga, o conteúdo do urinol pela janela, na noite que murmulhava feito uma concha" (SCHULZ, 1996, p. 28).

Notam-se, no breve trecho apresentado aqui, elementos constitutivos da obra de Schulz, com suas mudanças de nivveis textuais. De um lado, há a encenação do olhar infantil sobre diversos objetos e elementos de seu ambiente, e, de outro, a abertura de um canal para além das aparências, em que esse olhar adquire uma dimensão ritualístico-religiosa que transporta a existência prosaica, pelo menos temporariamente, para um contexto mitológico amplo. Nele, sua experiência individual apenas expressa "uma" das incontáveis formas singulares de um ciclo eterno. O episódio termina com um ato banal, mas, em razão do enriquecimento anterior, com certo poder simbólico sem que, portanto, os diferentes nós narrativos e níveis textuais se suspendam numa conclusão unívoca. O olhar ingênuo, sua elevação a momentos de grandeza universal e o reingresso na observação prosaica, tudo isso contado e formulado pelo "mesmo" narrador, resultam na típica indiferenciabilidade textual de Schulz. O motivo do labirinto em seus diversos desdobramentos, bem como o da sombra, já indica, na parte inicial, a natureza básica desse espaço entre a redenção e o desvario. Não podemos nos esquecer de que se trata sempre de uma narrativa baseada na visão do filho, que apresenta ora a percepção e a linguagem própria de um jovem, ora as de um adulto, sem que essa mudança seja tematizada no texto. Assim, a mitologização, realização adulta, parece fazer parte da imaginação "natural" da criança, e o "narrador adulto" permanece oculto, ou seja, não se manifesta e não explica sua intervenção, mas cobre ou reveste as impressões do jovem com o mito.

Schulz configura assim seu espaço narrativo primeiro pelas voltas dadas pelo pai num labirinto, o caminho quase impossivel de ser encontrado até seu ambiente pessoal, passando pelas casas indistintas e pelo perigo de se perder nos inúmeros quartos até achar sua cama, lugar do enfermo. Lá, inicia-se a exploração de seu interior: "o seu pensamento penetrava secretamente nos labirintos de seus próprios intestinos" (p. 26), dada a natureza de sua doença. Tal encontro com sua própria condição, marcado pela ameaça da morte, provoca nele um último ato de rebelião contra o destino - o que o torna, pelo menos para o narrador, um profeta temido do Velho Testamento, um titã poderoso e irado que se levanta contra forças ameaçadoras.

Schulz usa aqui uma série de expressões da natureza como "turbilhão de braços", "nuvem de brandimentos desesperados" ou "mãos que rasgavam o céu em pedaços" para descrever a última erupção de força do pai. No fim, seja como alegoria da sua entrega ou renúncia, seja como gesto puramente banal, o pai lança "uma terrivel praga" de seu interior, esvaziando o urinol "pela janela, na noite que murmulhava feito uma concha" (p. 28).

Depois disso, o filho narrador descreve seu processo de desparecimento. "O meu pai estava definhando, murchando a olhos vistos" (p. 28). E toda a família nota que "o nosso pai começou a encolher, ficando cada dia menor, como uma noz que resseca dentro de casa" (p. 29). Ele se retira do convivio e sua ausência passa quase despercebida.

Simplesmente deixamos de levá-lo em conta, a tal ponto se afastara de tudo quanto é humano e real. Nó por nó ele se desprendia da gente, ponto por ponto perdia os laços que o ligavam à comunidade dos homens. O que dele restou, um 
pouco daquela carcaça do corpo e um punhado de extravagâncias absurdas, podia desaparecer um dia, despercebido como um pequeno, cinzento monte de lixo de canto, que Adela levava diariamente para o monturo (SCHULZ, 1996, p. 31).

Aqui, já no início da primeira coletânea, o pai parece estar próximo da morte e do desaparecimento. Mas é apenas 26 episódios depois que Schulz encerra o ciclo paterno com um capítulo intitulado "A última fuga do meu pai" (SCHULZ, 1994, p. 222-227). Assim, o corpo textual emerge como contrapeso do esvair físico.

$\mathrm{O}$ isolamento do pai - que de certa maneira fora obrigado pela empregada Adela a ocupar apenas um quarto pequeno e afastado na casa da família - e sua lenta agonia deixam o filho perplexo e desorientado. "Cercou-nos de novo, por todos os lados, o cinzento fúnebre da cidade" (p. 40). Uma "estranha sonolência" (p. 41) toma conta de tudo, um tempo sem face e referências.

Um elemento central na passagem do narrador para fora dessa desordem em direção à adolescência, a um posicionamento próprio parece ser um certo Livro, na versão original em polonês chamado de księga, "o grande livro sábio", "livro sacro" ou o "livro dos livros". Com efeito, o narrador se lembra, "no amanhecer da infância" (SCHULZ, 1994, p. 17), de um livro de tamanho grande, um fólio, o qual o pai não apenas lia para a criança, como também era capaz de fazer emergir dele belas e coloridas imagens, criando assim um mundo próprio ao tornar as folhas soltas um universo interligado, vivo e pulsante. Agora, mais velho, o filho fantasia novamente acerca desse livro: "Comecei a delirar confusa e intrincadamente, no meio de um tormento e de um rancor inútil, com o velho Livro perdido" (SCHULZ, 1994, p. 19). Parece ser impossivel encontrar o livro. O pai oferece-lhe então um livro grande.

Era a Bíblia. [...] Ergui ao pai meus olhos, cheios de reprovação: - Você sabe, pai - gritava-, você sabe bem, não se esconda, não se esquive! Este livro traiu você! Por que você me dá este apócrifo contaminado, uma das mil cópias, esta falsificação inábil? Onde você escondeu o Livro? (SCHULZ, 1994, p. 20).

A reação do pai é virar os olhos, um gesto que pode ser interpretado de diversas maneiras. Pode ser expressão de impaciência, de simples ignorância da existência de tal livro, seguida pela explicação, dada algum tempo depois, de que no "fundo, existem só os livros. O Livro é como um mito em que acreditamos enquanto jovens, mas com o correr dos anos ele deixa de ser tratado com seriedade" (SCHULZ, 1994, p. 20).

Goślicki-Baur (1975, p. 90), por sua vez, compreende o gesto e a negação do Livro como defesa de sua autoridade e expressão de "seu medo de uma perda de poder". Em todo caso, o narrador nos informa logo depois que já possuía o Livro, no momento da negação da existência deste pelo pai. Mas esse agora é chamado pelo narrador de "tal trapo do Livro, os tais restos miseráveis" (SCHULZ, 1994, p. 20), um objeto desgasto e estropiado.

O encontro desse Livro mutilado passa pela empregada Adela e é desencadeado pelo erotismo e carga sensual que ela provoca no narrador.

Um dia deste inverno encontrei Adela arrumando o quarto, com uma escova na mão, apoiada na estante com alguns papeis rasgados. Inclinei-me olhando sobre seu ombro, não tanto pela curiosidade como para embriagar-me de novo com o cheiro de seu corpo, cujo encanto jovem revelou-se aos meus recém-despertos sentidos (SCHULZ, 1994, p. 20-21). 
Ambos se debruçam sobre uma reportagem com ilustrações de um elixir e de seu efeito milagroso sobre o crescimento capilar, cheia de alusões semânticas a motivos bíblicos, como "preces fervorosas" que tinham sido ouvidas, "a praga" que tinha sido removida graças a "iluminação" etc. Tudo isso resulta numa conclusão surpreendente: "de repente me veio um pensamento tão chocante que fiquei perplexo: era o Livro, suas últimas páginas, seu suplemento não oficial, os fundos de uma oficina cheia de restos e trastes!" (p. 22). E Adela, ao ser questionada sobre a origem do livro, informa que "ele sempre esteve aqui, e a cada dia arrancamos suas folhas para embrulhar a carne no açougue ou o lanche do pai..." (p. 22).

Embora o prosaico suplemento ou catálogo não tivesse "nenhuma página do verdadeiro texto" (p. 22), revela-se mesmo assim capaz de se elevar sobre "a esfera das coisas cotidianas, rumo às regiões da poesia pura" (p. 23). Entre milagres de aleijados que voltam a caminhar, o fólio também apresenta uma série de objetos à venda, como cítaras e harpas usadas outrora como "instrumentos dos corais angélicos" (p. 23), personagens como o mestre da magia negra Bosco de Milão e "seu longo e obscuro discurso" (p. 25) e uma adepta da Antroposofia com um livro de conselhos sobre o "adestramento dos homens" (p. 26).

Podemos compreender a apresentação irônica de tais anúncios como índice da profanação do sagrado nos tempos modernos: em vez de anjos cantando, temos fios telegráficos e músicas de sucesso ["Daisy, Daisy, me dá a resposta..." (p. 24)] ou ["Margarete, tesouro da minha vida..." (p. 25)] bem como o realejo, instrumento de repetição que se tornou o mais popular dessa época. Em vez da variação e do autêntico, a repetição mecânica.

A desmitologização do mundo, a redução de sua complexidade, a substituição do sagrado pela psicologia barata e a venda de produtos, disfarçadas visual e semanticamente de revelações, são narradas, aqui, com imagens e formulações bíblicas degradadas. Mesmo assim, o narrador afirma que "era o Livro verdadeiro", apenas num estado de "humilhação e degradação profunda" (p. 27). Assim como "o original", a partir do qual todos os outros livros se desdobram, "vive e cresce" (p. 27), assim também um catálogo como esse, uma cópia barata emprestada, se dirige para o original, "se desenrola na sua leitura, as suas fronteiras são abertas de todos os lados para todas as correntes e flutuações" (p. 29).

Vimos, nos exemplos apresentados, constantes mudanças de níveis referenciais e textuais. De um lado, há o olhar infantil que penetra uma esfera para além das aparências estendendo e ampliando suas observações prosaicas através de um deslocamento extático. Nesse processo, elas adquirem uma dimensão ritualístico-religiosa frequentemente descrita de forma irônica, mas igualmente cheia de momentos de grandeza universal. Posteriormente, há um retorno ao prosaico que deixa o leitor em dúvida sobre a instância textual pela qual deva se orientar. Assim, a imagem do pai escarranchado sobre o enorme urinol de porcelana é inserida no contexto dos profetas do Velho Testamento: um homem derrubado pela ira de Deus que, num último gesto de revolta contra seu destino mortal, rasga com suas mãos o céu em pedaços, para logo depois despejar, de pijama desabotoado, o conteúdo do urinol pela janela.

Ele faz isso com "uma terrivel praga", e na noite "que murmulhava feito uma concha" (SCHULZ, 1994, p. 28), ou seja, Schulz reveste aqui a ação prosaica com um leve eco semântico do êxtase anterior, mantendo o equilíbrio entre o olhar infantil ingênuo e a dimensão superior, o arcaico e o cósmico. 
O mesmo procedimento literário vemos em relação ao Livro; ele é, de um lado, um objeto concreto de tamanho grande, um fólio, que o pai apresentava à criança em uma leitura que fazia emergir belas e coloridas imagens num universo interligado, vivo e pulsante; e, de outro lado, um catálogo ilustrado de produtos miraculosos e um mito. Schulz sempre transcende tais lacunas entre os diferentes niveis textuais e conceituais apontando para a potencialidade das coisas e dos eventos. Assim, o catálogo é o Livro verdadeiro, mas apenas num estado de humilhação e degradação. O elo entre ambas as versões é a ideia de que cada texto se desdobra, se desenrola e fica aberto para possíveis flutuações para todos os lados, dirigindo-se ao original e assim faz parte, mesmo como forma degradada atual, da potencialidade do original, ou seja, do amorfo texto primordial.

Para Schulz, apenas a linguagem poética é capaz de religar o mosaico do cotidiano com o todo universal ou cósmico, de certa forma em um anseio da palavra pela sua matriz, pelo seu lar primordial. Mas, ir ao encontro desse lar, fundo ou pátria nos textos de Schulz não significa encontrar uma iluminação ou esclarecimento. Em vez disso, surgem grandes incubadoras de histórias, textos que se referem uns aos outros,

[...] romances sem título, epopeias enormes, pálidas e monótonas, bilinas amorfas, caraças disformes, gigantes sem rosto ocupando o horizonte, livros-lendas, livros nunca escritos, livros-eternopretendentes, livros andantes e perdido in partibus infidelium... (SCHULZ, 1994, p. 67-71).

Mas o potencial precisa de formas para vir à tona, máscaras que se encenam e representam seus papeis, consciente de sua atuação.

Assim, uma aura onipresente de ironia emana desta substância. Há uma atmosfera de palco sempre presente, de conjuntos vistos de trás, onde os atores zombam do pathos de seus papeis depois de despir o figurino. O simples fato da existência individual detém uma ironia, uma brincadeira, uma careta de palhaço (FICOWSKI, 1990, p. 113).

Não há, portanto, como compreender as narrativas de Schulz sem o aspecto teatral, a autoconsciência de sua própria encenação e a ironia como distanciamento refletido e jocoso, de caráter quase paródico, em relação à diferença insuperável entre a substância, a essência e suas diversas manifestações. Assim, os textos de Schulz são impregnados com uma fosforescência, encenando infinitamente "este ofegante carnaval tardio, este pânico das salas de baile da madrugada e a torre de Babel das máscaras, que não podem encontrar seus verdadeiros trajes" (SCHULZ, 1994, p. 137). No palco textual do autor vemos então figuras disfarçadas e momentos que, de forma irônica, cômica e trágica participam do "segredo", do "mítico atemporal", do "grande sentido universal" da realidade poética, apenas para, logo depois, se revelarem atores adventícios e falsas esperanças na rede do eterno curso dos fios narrativos. Schulz (1994, p. 137) nos apresenta assim

[...] um grande teatro ambulante mentindo com poesia, [...] uma enorme cebola colorida descascando-se camada por camada com um panorama novo. Nunca se pode alcançar o âmago. Atrás de cada bastidor, quando murcha e enrola-se com sussurro, descortina-se um panorama novo e radiante, vivo e verdadeiro por um momento, até que, apagando-se, denuncie a sua natureza de papel. E todas as perspectivas são pintadas? desenhadas?... 


\title{
"WHAT A MIGRATION OF FORMS, TUMULT, UPROAR AND CONFUSION IN THAT STORY!" Following THE NARRATIVE THREADS OF BRUNO SchulZ
}

\begin{abstract}
Schulz's work is often situated between the poles of individual memory and universal myth. Far less attention is given to the central ironic and parodist elements of his texts as part of a theatrical staging. This article aims therefore to analyse the frequent changes of textual levels, from childish observations to ecstatic outburst as part of a literary strategy where figures and moments emerge ironic, comic and tragically, yearning to participate in the "great universal sense" only to be soon revealed as adventitious actors and false hopes caught in the eternal web of narrative threads.
\end{abstract}

Keywords: Bruno Schulz. Myth. Irony.

\section{REFERÊNCIAS}

DULAIMI, K. Der Mythosbegriff im Werk von Bruno Schulz. 1975. Tese (Doutorado)-Universidade de Munique, Munique, 1975.

FICOWSKI, J. Bruno Schulz: ein Künstlerleben in Galizien. München: Hanser, 2008.

FOER, J. S. Everything is illuminated. Nova York: Harper Perennial, 2003.

FOER, J. S. Tree of codes. Londres: Visual Editions, 2010.

GOŚLICKI-BAUR, E. Die Prosa von Bruno Schulz. Bern: Slavica Helvetica, 1975.

GRIMM, R.; HERMAND, J. (Ed.). Die Sogenannten Zwanziger Jahre. Bad Homburg: Gehlen, 1970.

LUKAS, K. Mythos, archetyp und translation. Die Prosa von Bruno Schulz im Kontext der Ideen von Thomas Mann und Carl Gustav Jung. Convivium. Germanistisches Jahrbuch Polen, 2010, p. 213-234. Disponivel em: <http://www. staff.amu.edu.pl/ macbor/convivium/archiv/2010/2010_inhalt.html>. Acesso em: 23 mar. 2012.

MANN, T. Freud und die Zukunft. In: FREUD, S. Abriss der Psychoanalyse. Frankfurt und Hamburg: Fischer 1953.

OLCHANOWSKI, T. Die Interpretation des Vater-Mythos in der Prosa von Bruno Schulz unter Anlehnung an C.G. Jung. Białystok: Trans Humana, 2001.

SCHMID, U. Die Realisierung der modernen Metaerzählungen bei Bruno Schulz (Kant, Freud, Kafka). In: HODEL, R. (Ed.). Zentrum und Peripherie in den slavischen und baltischen Sprachen und Literaturen. Bern: Slavica Helvetica, 2004. p. 119-134.

SCHULTE, J. Eine Poetik der Offenbarung: Isaak Babel', Bruno Schulz, Danilo Kiš. Harrassowitz: Wiesbaden, 2004.

SCHULZ, B. A mitificação da realidade. Studio, n. 3-4 (BN, 368), 1936. Tradução de Siewierski (1996).

SCHULZ, B. Republik der Träume. München: Hanser, 1967.

SCHULZ, B. Die Zimtläden und alle anderen Erzählungen. Aus dem Polnischen übersetzt von Josef Hahn. Frankfurt am Main: Fischer Taschenbuch Verlag, 1981. 
SCHULZ, B. Sanatório. Rio de Janeiro: Imago, 1994.

SCHULZ, B. Lojas de canela. Rio de Janeiro: Imago, 1996.

SCHULZ, B. Die Wirklichkeit ist Schatten des Wortes. Aufsätze und Briefe. Ed. Jerzy Ficowski. München: Deutscher Taschenbuch Verlag, 2000.

SCHULZ, B. Die Mythisierung der Wirklichkeit. In: SCHULZ, B. Die Zimtläden. Aus dem Polnischen von Doreen Daume. München: Hanser, 2008. p. 193-197.

SCHUlZ, B. Ficção completa. Tradução Henryk Siewierski. São Paulo: Cosac Naify, 2012.

SIERWIERSKY, H. Posfácio. In: SCHULZ, B. Lojas de canela. Rio de Janeiro: Imago, 1996. p. 142-173.

WAGNER, H. Jonathan Safran Foer talks tree of codes and conceptual art. Vanity Fair. November 10, 2010. Disponivel em: <http://www.vanityfair.com/online/ daily/2010/11/jonathan-safran-foer-talks-tree-of-codes-and-paper-art.html>. Acesso em: 3 jan. 2012.

Recebido em dezembro de 2013. Aprovado em dezembro de 2014. 